\title{
LEXICOGRAPHY AND GENERATIVE GRAMMAR II: CONTEXT AND CONNOTATION IN THE DICTIONARY *
}

\author{
Robin Lakoff $\dagger$ \\ University of Michigan \\ Ann Arbor, Michigan 48108
}

One might make the claim with some justice that every act a speaker performs of choosing a word in a discourse is an act of propaganda. Sometimes the propaganda is deliberate, sometimes unconscious; sometimes overt, sometimes covert. But generally if we are at all careful speakers or writers, when we use a word we hope it means what we want it to mean: no more no less; we hope to create a specific effect.

I am, of course, speaking only about content words, and probably, to be fair, only a subset of these, those that involve judgments by speaker or hearers about the subject of the discourse. But in this category, it is extremely difficult to avoid "loading" your language-you must express your opinion willy-nilly, and the only questions to be asked are: what is your opinion? and, how strongly do you want to express it? On the basis of the answers to these questions you will decide what words you want to use.

And obviously, the wrong choice can be dangerous, sometimes only to the extent of frustrating the speaker and confusing his listeners, as he tries to make his point; but we all can think of cases where the wrong choice of a word threw politics into upheavals or influenced large classes of people in undesired ways; or, conversely, where the precisely right word accomplished what armies could not. So one must know how one's words will be received.

The only problem is that one is not necessarily born with this knowledge, nor does one necessarily even acquire it fully in the normal course of language acquisition. And it often happens that even a speaker who considers himself relatively sophisticated in the arts of word-magic will be uncertain about the precise meaning of a particular word: is it good? bad? strong? weak? does it make special assumptions? is it neutral or somehow 'loaded'? pedantic? casual? To put it in a nutshell-what is the likely reaction to the use of this word, and how would this change if another, more or less synonymous, word were substituted? Of course, what we find as we hunt around seeking effect or safety is that there are no synonyms. Every word has its own ambience, and we must pick carefully among the choices at hand-there are right ones and wrong ones, and seemingly trivial distinctions loom large when important matters are at issue. So what is our speaker (or writer) to do? He doesn't want to be an ignoramus, or a firebrand, or a bore, or a pedant ... he wants to say just what he means, but he isn't sure which word of several related ones to select. Where does he go for advice?

About the only avenue open to him is the dictionary. The dictionary, he

* Written while the author was in residence at the Center for Advanced Study in the Behavioral Sciences, Stanford, Calif., and on the Linguistics faculty at the University of Michigan.

† Present address: University of California, Berkeley, Calif. 94720 
has learned in school, tells what words mean. Well, that's just what he wants to know!

What I want to look at now is what happens when our hypothetical propagandist consults his dictionary. To what extent, and in what ways, does it help him find what he needs to know? And if to some degree it fails, is this failure to be expected? What can we expect from a dictionary? What ought its function to be? What can't a dictionary do, and why?

We should, at the outset, distinguish the different aspects of the meaning of lexical items, so that later we can see which ones a dictionary entry normally takes cognizance of, which it ignores. We must first separate the denotation or assertion from the connotation or pragmatic presupposition. Consider, then, a word like the verb know, as in sentence (1):

(1) Bill knows that Nixon is President.

Let us contrast this with another sentence, using a somewhat different verb:

(2) Bill believes that Nixon is President.

Now in both these sentences we are, essentially, asserting the same thing of Bill: that he thinks Nixon is President. As far as assertion goes, then, these two sentences might be synonyms. But of course they aren't, and the reason they aren't is that the assumptions each makes about the truth of Bill's thoughts are different. In (1), it is implicit-that is, pragmatically (and otherwise) presupposed-that the assertion is justifiable: the speaker "goes along" with Bill in his belief.

But in (2) the speaker is at best neutral: he doesn't take a stand on the correctness of Bill's belief. If it later transpires that Nixon was, at the time of the speaking of (1) or (2), actually not President, one might accuse the speaker of (1) of being himself mistaken, along with Bill. With (2), the speaker is not subject to the charge. But notice that, even in a supposedly "neutral" sentence like (2), the speaker can get in trouble: if indeed it is universally accepted at the time I say sentence (2) (as it probably is at the time I write this paper) that Nixon is in fact President, the use of this sentence is rather peculiar. My use of believe-in effect, my begging the question as to the truth of the assertion, Nixon is President-when in fact I and everyone else knows the assertion is true raises nagging doubts in the hearer's mind. It suggests, in fact, that 1 , the speaker, suspect that Nixon is not President, and that Bill is in fact wrong. This connotation is absent in sentences involving a less-than-universally held assumption, like (3):

(3) Bill believes that Nixon is a warmonger.

In this sentence, the use of the verb believe implies that the speaker really is neutral about Bill's belief. The contrast between (2) and (3) indicates that words can change their connotations depending upon the assumptions normally made in the community of speakers among whom the word is used. A word appropriate under one set of cultural or societal assumptions becomes odd under another. And similarly, while saying (1) is unlikely to get anyone into much trouble with anyone at present, saying (4) will endanger a speaker in many circles (and endear him in others) where (3) will not cause his hearers to have any reaction. 


\section{(4) Bill knows Nixon is a warmonger.}

I have pointed out certain differences in the meanings of the two lexical items know and believe. Both assert that the subject of the verb entertains a belief. Know further presupposes the truth of that belief. A dictionary clearly ought to distinguish these verbs to this extent. Whether it ought to make still other distinctions, and to what extent it ought to make this one, is a question we shall examine in more detail below.

It is of interest to the practical as well as the theoretical lexicographer, however, how many things besides the denotative meaning (assertive force) of a word go to comprise its lexical meaning. We have discussed pragmatic presupposition and socially-related assumption. Related to the latter are other ways in which the interactions between members of a society-apparently nonlinguistic information-affect the interpretation of a lexical item by its hearers. We must remember that words, and larger discourses, are used to create an effect, and the meaning of a word in its strict denotative sense creates only part of that effect; the rest is supplied by social and environmental factors, and it is here that one can get into the most trouble by ignoring seemingly peripheral issues.

There are, as Grice ${ }^{1}$ has shown, rules of conversation, which speakers follow much as they follow rules of grammar; deviations are noticed and punished, one way or another. Related to these are rules of politeness, again normally adhered to. One example of a rule of conversation, and a possibility for violating it, has been discussed already. We noted earlier that sentence (3) was, in the context of today's real-life world, somehow aberrant although no one's assumptions about the real world were violated. The reason why this is true is that there is a rule of conversation that reads, approximately, "Say all that you mean." To say less, to understate, in some kinds of cases, is to imply that you mean less. If we are talking about something that is universally assumed to be true, the speaker, in forming sentences like (1)(4), must somehow take cognizance of this universal assumption in the verb he uses; if he fails, even by oversight, the result will be as though he were implying his oversight was somehow purposeful. If such a law of conversation is violated, the hearer will search for some way to reconcile the aberrant use with his normal assumptions, and will find, if he can, an interpretation that renders the use non-aberrant-in this case, he will most likely arrive at an interpretation implying that the supposed universal truth is, according to some arcane knowledge only the speaker is privy to, not really true.

We also must know whether we are speaking politely or not. Normally, the rules of proper behavior require that we be as polite as possible, that we do not create offense in the way we speak - though there are special circumstances in which these rules too are relaxed. Also, there are degrees of politeness, and one must know the degree expected of one. Different lexical items will be appropriate depending on how polite one chooses to be. In languages like Japanese, distinctions between words on the basis of politeness extend throughout the vocabulary; it is almost impossible to utter a sentence without making explicit the level of politeness to which one is adhering. In English, only select lexical items are graded according to politeness, but the penalties for misuse are still strong. Words apparently synonymous-and so defined-are sometimes only denotationally so, one being politer than another. 
There are numerous forms politeness takes in English, only some of which are of immediate interest to the lexicographer. We can mention a few.

First, there is euphemism. If we feel uncomfortable with a general concept, we will invent a euphemism for it. Correlated with euphemisms are derogatory expressions. So often, in these cases, we have a triple: derogatory expressionneutral term-euphemism. Consider groups like the following in this regard:
I. stink
smell
odor

$$
\begin{aligned}
& \text { II. propaganda } \\
& \text { instruction } \\
& \text { information }
\end{aligned}
$$

\author{
III. cheap \\ inexpensive \\ economical
}
IV. broad woman lady

In some of these cases-I, III, IV, V-to use the top word on the list is to commit an act of impropriety under conditions where polite behavior is expected. In the other cases, to use the top word on the list is not an act of impoliteness, but rather is an admission that the act under discussion is not thought of as a good act. In the "impolite" cases this is also frequently true: an "impolite" word is such precisely because it expresses the speaker's distaste for the concept, while the neutral word attempts to render it colorless, and the euphemism is used to give the word good connotations. Whether a word will be considered polite or impolite, euphemistic or derogatory, will change with time and cultural assumptions, and may vary from individual to individual. So a lot of people have grown up with the idea that it was vulgar to use the words sweat or stink. But more recently, these words have been shorn of their bad connotations in the usage of many people, and their euphemismsperspire in particular-have started to seem like jokes at the expense of the overrefined. What is one to do about such items in the dictionary? And, as a more theoretical question, how are we to deal with this sort of semantic change, in which a word loses its bad connotations through societal evolution? How is this related to non-socially motivated change in the non-denotational meaning of lexical items, which is also quite frequent. It is general knowledge that the word egregious once meant "conspicuous," with go good or bad overtones. But at present it means "conspicuously bad." The denotation has now become part of the connotative meaning, or pragmatic presupposition, and the new denotative sense is "bad." We all can imagine mechanisms for describing denotative meaning-change; but formal description of changes in the connotative and contextual senses of words is harded to imagine.

While this is not in itself a problem for the practical lexicographer, there are plenty of related questions that are problems for everyone who deals with word-meanings. To return to the question of societal context, everyone knows there are words that cannot be used by everyone or cannot be used everywhere. Impolite words are one example of the latter type. Pedantic words are another. Just as it is inappropriate to say, normally, (5), it is equally bad in a different way to say (6), since in both cases the speaker means (7), and would generally be expected to say it.

(5) Wolf down some more cake.

(6) Ingest some more cake.

(7) Eat some more cake. 
Most dictionaries, quite properly, have ways of indicating that words are substandard or restricted to certain groups, by economic or geographic areas. Everyone knows the impression he would make by saying aint, and most people know it marks you as a New Yorker to be heard saying sliding pond for slide. There are other marked vocabulary items, perhaps more dangerously restricted: to use a word like adorable marks one, in many social groups, as either a woman or a homosexual. To say doggie marks one as a child, or childish person. If slang, substandard, and (geographic) dialectal terms are typically so indicated in dictionaries, these others probably ought also to be marked somehow.

It is also true that a single lexical item may change the normal relationship between its denotation and connotation under special stress. Examples like the following have been discussed by Fillmore: ${ }^{3}$

(8) I didn't blame Jóhn for dropping the bomb.

(9) I didn't bláme John for dropping the bomb.

The only difference in the superficial forms of these sentences is in their stress: (8) has "normal" stress, falling on John; (9) has special stress on blame. In (8), the word blame asserts that the act (of dropping the bomb) was a bad thing, and presupposes it was John who did it. In (9) it is just the reverse: stressed blame presupposes that the act was bad, and asserts that it was John who did it. (Of course, in these sentences blame is negated, so that the final interpretation of the assertion is the reverse in both cases). Now we have a single word, phonologically speaking, which, in different environments behaves semantically very differently. ${ }^{1}$ Shall we treat it as two lexical items, blame 1 and blame 2? No dictionary I know of does this, and no sane linguist would suggest doing this-in either a theoretical or practical treatment. There is a systematic relationship between the placement of stress and the relationship between the presupposition and the assertion. Fillmore has convincingly demonstrated this for one class of verbs, the verbs of judging; it can be shown to hold for many other classes as well. We don't have to treat blame as two words, since we can relate the two uses in the grammar. But there should be some way to take note of these different senses of blame. Some dictionaries have found ingenious ways of expressing the distinction. Among the numerous words of judging, only some exhibit this switch under stress. Others have only one of the two meanings. The verb censure on the one hand, and the expression place the responsibility for- on, hold responsible for on the other, are in this relationship: censure is like stressed blame, the expressions with responsible, responsibility like unstressed blame.

(10) I didn't hold John responsible for dropping the bomb.

(11) I didn't censure John for dropping the bomb.

While neither of these expressions is a perfect equivalent of blame, they are parallel to the two sense of blame in terms of the relationship between assertion and presupposition we have discussed. (10) is close in this sense to (8) but not (9); (11) is reasonable equivalent of (9), but not (8). One dictionary at least $\S$ employs this distinction in listing two meanings of blame:

\$ All dictionary entries cited are from Webster's Seventh New International Dictionary, 1963. Springfield, Mass.: G. \& C. Merriam Co. 
blame. . . . 1. to find fault with: CENSURE 2a: to hold responsible for [ $\sim$ him for everything] $b$ : to place responsibility for $[\sim s$ it on me]

While there is no mention of the role of stress in this dictionary entry, it does manage to distinguish correctly between the possible meanings of blame. So a dictionary can deal with presuppositions, of some kinds at least, sometimes at least.

But in other respects the dictionary is often less satisfactory, sometimes more than others. So often dictionaries lump together words that are similar or identical in denotation, but not in presupposition: One dictionary calls stubborn a synonym of pigheaded. If this were indeed the case, the following two sentences would be identical in sense and in the conditions under which they were appropriately used.

(12) He tried stubbornly to better himself.

(13) He tried pigheadedly to better himself.

(12) implies merely that he struggled against difficult odds, in the face of great opposition. It can and perhaps usually is complimentary, and can perfectly well be used if the subject eventually did succeed. (13), on the other hand, suggests that the subject was struggling against really, rather than only apparently, insuperable odds: the speaker makes the assumption that the struggle was stupid and doomed to failure. In (13), the normal assumption would be that the subject eventually failed, since the speaker assumes that it was stupid of him even to try. So (12) might be used, for instance, of Abraham Lincoln; it would be most odd to use (13) so (for a modern biographer). A dictionary must do better than this, since this pairing of these two words, without explanation, can easily cause one to use one of them or both of them wrong. It may be argued that "everyone knows the difference." But if everyone does, why have a dictionary at all? We shall have more to say later about who benefits, and how, from the dictionary; but it is always important not to lead anyone astray.

Sometimes, in this regard, a dictionary does very well. The same dictionary that did a bad job on pigheaded and stubborn, under pigheaded, makes these distinctions quite beautifully (omitting pigheaded) under obstinate.

Syn OBSTINATE, DOGGED, STUBBORN, PERTINACIOUS, MULISH mean fixed and unyielding in course or purpose. OBSTINATE implies usu. a perverse or unreasonable persistence; DOGGED suggests a tenacious frequently sullen persistence; STUBBORN implies sturdiness in resisting attempts to change or abandon a course or opinion; PERTINACIOUS suggests an annoying or irksome persistence; MULISH implies a thoroughly unreasonable obstinacy.

Notice that in this comparison most of the important points of contrast are covered, clearly and succinctly. First, the attitude of the speaker toward the action: the use of sturdy, a word with good connotations with stubborn (hence a sentence like (12) above is possible) (of course, one also has to know the normal connotations of the words used in the definitions!); annoying or irksome, with pertinacious; that is, connotations suggestive of the speaker's normal attitude; and connotations suggesting the manner in which the act is performed: sullen, for instance, with PERTINACIOUS. Now if we know (from outside the dictionary) the normal rules of politeness, we know that 
normally we do not gratuitously say bad things about our addressee, though we might about someone else. So (14) is more normal than (15), while (16) is a normal sentence, under the correct situations.

(14) You are stubborn.

(15) You are mulish.

(16) $\mathrm{He}$ is mulish.

Of course, if driven to exasperation, one might well use (15); but the very definition of "exasperation" suggests a state of mind in which conventions of politeness are purposely or otherwise abandoned. So our knowledge of realworld politeness conventions, and further knowledge of when they are abandonable, coupled with additional purely linguistic knowledge that enables us to differentiate between stubborn and mulish, allows us to use these words in the right place. But we must know more than merely what the dictionary tells us in order to know how to talk, in this instance. There are other instances too in which one cannot hope to rely on the dictionary alone: consider how it is that we know that sentences like (17)-(19) are reasonable, while $(20)$ is aberrant.

(17) Since John is a congressman, he can easily afford that $\$ 1,000,000$ house.

(18) Since John is a congressman, he can introduce that bill.

(19) Since John is a congressman, he is over 25 years old.

(20) Since John is a congressman, he is bald.

A dictionary will define congressman as "a member of Congress" or "of the House of Representatives," and further define Congress as "the legislative body of the US government," or some such. This is about all we expect a dictionary to do, but notice that it gives us no help at all with the four sentences above: it doesn't tell us how the first three differ from the fourth, or among themselves. Yet this knowledge is somehow incorporated into the definition of congressman. This brings up the question of what we can expect from a dictionary definition. One's first thought, perhaps instilled by the elementary school teacher who taught us about the dictionary in the first place, is that a definition somehow tells us all we need to know in order to use a word appropriately. But even superficial consideration shows us that this is not true, probably should not be true. All the examples given above attest to the fact that it is not true that a definition tells us how to use a word. Further, a dictionary definition does not tell us what a word means, in any comprehensive sense, since if it did, it would also automatically tell us how to use it appropriately. In many of the examples given already, the dictionary entry tells us less than we need to know: the untutored Martian arriving on earth could not consult the unabridged dictionary at the library and henceforth speak English like a native (even assuming he had elsewhere acquired a knowledge of English syntax); he would be unaware of presuppositions of many types, such as the ones distinguishing know and believe, or eat and gobble; he would be unaware of the rules of conversation and of politeness, and how they alter and affect the usability of dictionary entries in various social environments. And he would be unable to tell which of the sentences $(17)-(20)$ were normal sentences of English, and how they were interpretable when they were.

None of the sentences $(17)-(20)$ is interpretable from the dictionary definition. Perhaps, it may be suggested, an encyclopedia would provide help: telling us about real-world functions and uses is a job done by an encyclopedia, 
not a dictionary. Hays ${ }^{2}$ suggests that a dictionary supplies denotative definitions of words, an encyclopedia connotative. But we have seen that, in order to give any idea how a word is used, very of ten a dictionary must provide some information about connotations; and of course an encyclopedia must talk about denotation to be intelligible at all. In the case of congressman, though, even an encyclopedia would tell us that a congressman's job is to introduce bills (or the like), and that to be a congressman one must be over 25 years old. Hence, from these definitions we see how the sentences (18) and (19) make sense. But there will be no provision in the normal encyclopedia for distinguishing between (17), which is a reasonable if cynical utterance, and (20), which is nonsense. Here we must resort to some notion of real-world knowledge one somehow acquires about the dealings of congressmen, covered neither by a knowledge of their constitutional duties nor the eligibility requirements for running for congress. In the real-world situation of the U.S. government, we know that sometimes, as an indirect result of his officially delegated powers, a congressman can become very rich; but normally there is no reason to suppose that any function of a congressman causes him to become bald. But this is real-world knowledge, not a part of the definition of congressman in a dictionary or an encyclopedia. This example shows that there are aspects of meaning that cannot be treated in any reference work, that meaning goes beyond a formal definition of appearance, duties, privileges, etc.

Sometimes a dictionary definition seems both to tell more than is needed by the normal. English-speaking user, and less than needed by our naive Martian. One example is the definition, in the dictionary we have been citing, of egg:

la: the hardshelled reproductive body produced by a bird and esp. by domestic poultry; $b$ : an animal reproductive body consisting of an ovum together with its nutritive and protective envelopes and being capable of developing into a new individual capable of independent existence. c: OVUM 2: something resembling an egg 3 slang: FELLOW, GUY

Normally, one thinks of an egg as a food. This definition fails to mention this, and hence, fails to define the concept egg in a useful way.

But, the dictionary maker protests, he is not making up a dictionary for the naive Martian. He need not indicate that know is factive, because the normal speaker of English capable of using a dictionary at all knows this already; similarly he knows that an egg is good for eating. But he may not know the reproductive function of an egg, and he may not know how the meaning of stubborn differs precisely from that of mulish, and he may need to know the meanings of words somewhat out of the ordinary: frigorific, ineptitude, probang, strabismus, to select a few at random; or he may need to know the number of $m$ 's and $t$ 's in committee. Surely the typical user of a dictionary consults it for reasons like this, and it is only the picayune professional linguist who wonders about the treatment of know and gobble and egg. The job of the practical dictionary-maker is to reduce semantically complex forms to a combination of atomic elements; so egregious, a complex concept, is broken down into two simpler notions: conspicuous + bad, words with which the person consulting the dictionary is apt to be familiar, and some sort of clues (here, the adverbial form conspicuously indicates that this concept is presupposed, and the adjectival bad shows that this concept is asserted) to the relationship among these more-or-less atomic elements. But when it comes to 
defining these simpler elements themselves, the dictionary-maker is in greater difficulties. This is obvious in the definition of egg, where an essentially atomic element is defined by more complex elements. The dictionary-maker can, for practical purposes, assume that anyone who has a need to look up egregious knows the meaning of bad; but in a theoretical sense, the dictionary should also give the meaning of bad. Does it?

bad la: below standard: POOR b: UNFAVORABLE ( $\sim$ impression) c: DECAYED, SPOILED 2a: morally evil b: MISCHIEVOUS, DISOBEDIENT 3: INADEQUATE ( lighting) 4: DISAGREEABLE, UNPLEASANT ( news) 5a: INJURIOUS, HARMFUL b: SEVERE ( cold) 6: INCORRECT, FAULTY ( grammar) 7: ILL, SICK (feel $\sim$ ) 8: SORROWFUL, SORRY 9: INVALID, VOID

As is evident, all the "definitions" of bad involve semantically more complex and more restricted notions than the word itself being defined. So the dictionary sense of "definition" really is not a simple thing: when a complex word is being defined, it is broken down into simpler elements; when a simple word is defined, it is defined in terms of more complex elements. In most cases, assumptions and presuppositions of the kinds we have been discussing are either ignored completely or left to be inferred from information given, rather than stated directly; but even our Martian friend would be at a loss trying to figure out the meanings of most words from their dictionary definitions.

But our poor Martian would be equally at a loss consulting a pedagogical grammar of English to learn how to do English syntax, assuming Martians had none of the concepts of universal syntax and semantics shared by the speakers of all languages spoken on Earth. In writing a pedagogical grammar, there are of course numerous things we don't say: we don't, for instance, say that the coordinate structure constraint is in effect in English. We don't, therefore, feel a need to point out that sentences like (21) cannot be said in English even though they are, theoretically, semantically interpretable:

(21) Who did the boys Fred knows see John and?

We don't have to say that numerous semantic restrictions are in force: no pedagogical grammar of English warns the reader not to say (22):

\section{(22) Tomorrow I saw John.}

And these omissions, among others, distinguish a pedagogical grammar from a theoretical grammar, which, in one way or another, must somewhere provide the information above. Also, a theoretical grammar typically is assumed to break sentences down to their logically "underlying" forms. A theoretical grammar would provide the underlying phrase marker (FIGURE 1) for the superficial sentence "Floyd broke the glass." (Of course, this tree is most inadequate and approximate, even in terms of what we know now, let alone what we eventually hope to know; but it is the best we can do, for present purposes.) A pedagogical grammer could not, and should not, supply such information: its user has no need of it, need not know about abstract elements, logical underlying forms, and so on.

So a pedagogical grammar tells us much less than we innately know about the "grammar" of a language. Similarly, a dictionary tells us much less than we innately know about the "meanings" or words. In fact, the omissions in 
both are very much the same. We should perhaps look at a dictionary as a non-theoretical lexicon, as a pedagogical grammar is a non-theoretical grammar.

A theoretical lexicon tells us all that a dictionary does not: it breaks mean-

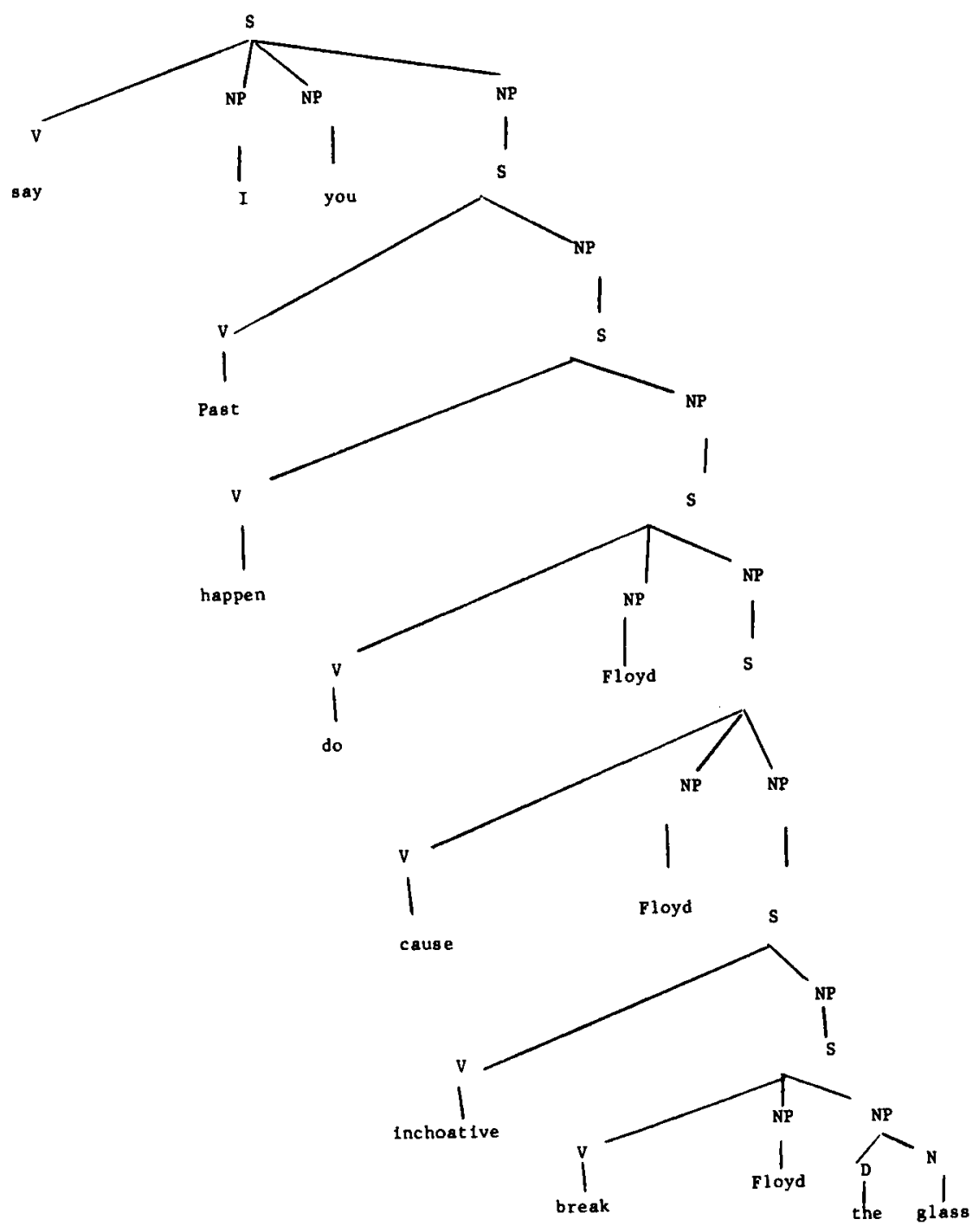

FIGURE 1. "Floyd broke the glass."

ings into their atomic elements, to such an extent that no word contained in a practical dictionary would remain in that form in the lexicon, but would be broken down considerably; it is unlikely that there exists in any language any lexical item truly atomic in meaning, and the many abstract elements (such 
as past in FIGURE 1) that are found in logical structures have no superficial form in the dictionary, though they would be found in the lexicon (just as they exist in the theoretical grammar, not in the pedagogical grammar). In both dictionary and pedagogical grammar, universal elements, things a speaker innately knows, are omitted, while they are part of the theoretical grammar and the lexicon.

What we conclude from this is that one must have two notions of meaning (or definition) as one must have two notions of grammar. The dictionarymaker, like the pedagogical grammarian, is concerned with those that are not a basic part of the human conceptual system. The purpose of a dictionary, as of a pedagogical grammar, is to fill in what the speaker cannot be expected to know already, the information the speaker does not bring to the book. Neither is the tool for the naive Martian. The naive Martian, on the other hand, will make good use of the theoretical grammar and the lexicon. These will tell him everything he needs to know, all the innate knowledge possessed and intuitively used by the human being. If the naive Martian finds either of these, he is requested to bring them to the nearest theoretical linguist, who has been looking for them for a long time and needs them badly.

\section{REFERENCES}

1. Grice, H. P. 1968. The logic of conversation. Unpublished mimeo, University of California, Berkeley.

2. Hays, D. 1970. Linguistic problems of denotation. In Progress in Linguistics, M. Bierwisch and K. E. Heidolph, Eds. : 81-85. Mouton. The Hague.

3. Fillmore, C. 1969. Verbs of judging. Papers in Linguistics.

\section{Discussion}

Mr. Francis: It occurred to me, apropos of semantic change, that a good many of the items about which there has been the greatest weeping and wailing over the degeneration of the language have changed in just this peripheral area of meaning, rather than in denotative meaning. One example is enormity, whose older meaning always was pejorative. One talked about the enormity of the crime, and so on. But I increasingly hear enormity being used just in the sense of enormousness, which always shocks me, because I feel this should always be a pejorative word, and it is often not so used. People speak, for example, about the enormity of the mortgage. 